true nature of the circulation are shown probably to have been added later, about 1627 or 1628 . This section will repay careful study. Dr. Whitteridge points out that it is not the similarities with De motu cordis which are of importance in determining the state of Harvey's knowledge in 1616 but the dissimilarities.

Another interesting section deals with Harvey's interest in surgery and pathology. It presents clearly the relationship between physician and surgeon at that time and how the instruction of surgeons rested with the physicians. She completely rejects the statement by O'Malley, Poynter and Russell that Harvey practised surgery himself and had actually performed lithotomy.

The final paragraph of the introduction states "these lecture notes show Harvey primarily as an observer rather than as an experimentalist. ... The rigorous discipline of argument and experiment of the De motu cordis was yet to come. That work was to be seen later as one of the first examples of modern scientific method. By comparison the lectures are backward looking. From Antiquity, through the Middle Ages and the Renaissance, medical education is unbroken in its tradition and in this tradition the lectures are enshrined. They do not reach beyond it to the dawning of the scientific attitude of the second half of the seventeenth century".

The book is handsomely and finely produced in a manner fitting for such a scholarly, impressive and instructive presentation of Harvey's lectures. It deserves great praise and is very strongly recommended.

RUSsell Brock

\section{PATHO-PHYSIOLOGICAL PHARMACOLOGY}

Kurzes Lehrbuch der Pharmakologie

Von Prof. G. Kuschinsky und Prof. H. Lüllmann. Pp. viii +332. (Stuttgart: Georg Thieme Verlag, 1964.) 33 D.M. HIS text-book attempts to present pharmacology
and those parts of toxicology which are relevant to
clinical medicine on the basis of patho-physiological
considerations, stressing structure-activity relationships.
By describing the actions of drugs as they affect physio-
chemical processes, in addition to giving an account
of their effects on the organs of the body, pharma-
cological observations are evaluated in their relationship
to biochemical and biophysical data. Considered from
this angle, pharmacology is seen to deepen the under-
standing of processes as they occur in health and disease,
in contrast to the notion that it consists merely in a
description of a vast variety of drug effects on various
parts of the body.

The references are mainly confined to review articles which would guide the reader to the original papers. Unfortunately, quite a few of the reviews quoted are ten or more years old. On the other hand, the authors have in many cases succeeded in integrating recent findings and modern theories into the presentation of their subject. For example, on the basis of the hypothesis of the storage mechanism of biogenic amines in the tissues, a brief and concise explanation is offered of the apparently contra. dictory influence of cocaine on the action of catecholamines, which is intensified, and on the effect of ephedrine and tyramine, which is diminished (p. 24). Tracings are well chosen and structural formulae of many compounds and their generic and trade names are included. Practical implications of the pharmacological actions, clinical usage and doses are indicated. Thus the chapter desling with the pharmacology of smooth muscle ends with an appendix which outlines the treatment of bronchial asthma, hypertension and migraine. Although these surveys are necessarily kept very short, phaeochromocytoma and unilateral kidney disease should have been included as curable types of hypertension.

Sections which have received a thorough and up-todate treatment include those dealing with the pharmacology of the autonomic nervous system and the kidney. Other parts are less comprehensive or frankly deficient. Some of them may be mentioned here: The clinician or student will scarcely be able to grasp the meaning of the brief paragraph which states that for a given stage of anaesthesia thermodynamic activity is approximately the same for the various anaesthetics, while solubility coefficients, oil-water distribution coefficients and partial pressures of the gases in the respiratory air show marked differences. The attitude to the use of amidopyrine is that common in parts of the European Continent and contrasts sharply with the fear of agranulocytosis that limits its use in other countries. The description of insulin does not include the principles involved in the preparation of the different kinds, nor does it mention that the lente type should not be mixed with other preparations and the reason for it. Treatment of diabetic coma by 50-100 units insulin intravenously and by subcutaneous injection, in addition to glucose, water and electrocytes, is surely inadequate. Though the significance of glucose-6-phosphate-dehydrogenase deficiency for idiosyncrasy to certain drugs and for the development of some haemolytic anaemias is stressed, the genetically determined differences in sensitivity to suxamethonium are not discussed. The actions of ACTH are only considered very briefly and its effect on cholesterol and ascorbic acid levels is not explained; its therapeutic uses are not sufficiently described, while half a page is allotted to thyrotropic hormone. In the section dealing with chemotherapeutic agents and antibiotics nitrofurantin should have been included, and para. momycin and perhaps the ampicillin treatment of typhoid mentioned.

The index is well compiled and includes the names of many preparations. In spite of the uneven treatment of the different chapters, the book is an up-to-date source of pharmacological knowledge and deserves a place on the shelf of medical practitioners and students.

L. WISLIOKI

\section{INFORMAL AND INFORMATIVE ASTRONOMY}

The Universe

Karl Taylor Compton Lectures. By Otto Struve. Pp. ix +159 (figures). (Cambridge, Mass: The M.I.T. Press (Massachusetts Institute of Technology), 1962.) 44s.; 4.95 dollars.

\section{HROUGH his numerous articles in Sky and Telescope}

Prof. Otto Struve has created a distinctly personal style of semi-popular writing in astronomy. These articles were intended to give to the informed public whatever happened to be the latest among professional astronomers. Physical ideas were set forth with lucidity, accompanied by ample arithmetical illustrations, but the mathematics was never allowed to go beyond an odd square root here and there. The style, though informal, was by no moans facile, because of an almost visible desire to be informative on the part of the author. Ideas succeeded one another with little regard for linguistic fluency, but this very shortcoming, like the occasional stammer of a great speech maker, enhanced rather than diminished the power of persuasion. This informal and informative style found its full expression in the 1959 Karl Taylor Compton Lectures, now available in book form.

Of the six lectures, that on binary stars is outstanding. Such an illuminating account could only have come from someone who had a deep sense of personal involvement 